\title{
Laser Hardening of Unimax Stainless Steel
}

\author{
Amessalu Atenafu Gelaw* and Nele Rath
}

Faculty of Engineering Technology, Electromechanical Engineering department, KU Leuven, Belgium

('Corresponding author's e-mail: just480@gmail.com)

Received: 19 June 2020, Revised: 11 May 2021, Accepted: 19 May 2021

\begin{abstract}
Nowdays, laser hardening of materials brings a comparative advantage over the conventional hardening technique. Fast cooling rate due to the heat distribution through its own bulk material, selfquenching property (rapid cooling without external water or oil), environmentally friendly characteristics since the procedure does not exhaust smoke, the localized heat input due to adjustable laser spot size to avoid distortion and minimum time to finish the operation are some of the advantages to mention. NIKO is a company specialized in making electrical products like socket outlets and switches by using injection molding techniques. Unimax is a kind of stainless steel used by the company to prepare some parts of the injection molding components like a Nozzle. This time, the company is using more and more fiberreinforced polymers throughout their product line. These composites are far stronger than the polymer, but on the downside, the fibers are quite abrasive. The objective of this research was to harden the Unimax stainless steel using Nd:YAG (neodymium-doped yttrium aluminum garnet) laser technique. First, the laser transverse speed and spot size were identified as the primary process parameters. Then, the traverse speed of 100, 150 and $400 \mathrm{~mm} / \mathrm{min}$ and spot size of 2164, 2169, 2288 and $2412 \mu \mathrm{m}$ were assigned with 3 replications. Afterwards, thermal simulation was done using COMSOL Multiphysics(C) followed by the real test on the metal bar. Therefore, the highest hardness of $650 \mathrm{HV}$ was obtained at a speed of $150 \mathrm{~mm} / \mathrm{min}$ and a spot size of $2169 \mu \mathrm{m}$ diameters. Finally, the corresponding depth of hardness and roughness values of $200 \mu \mathrm{m}$ below the surface and unmelt samples respectively were obtained.
\end{abstract}

Keywords: Hardening, Nd:YAG laser, Spot size, Stainless steel, Traverse speed

\section{Introduction}

Like the other sectors of the country, laser plays a big role in the economy of the country. Every year it is about multi-billions of dollars are raked by the laser industry. From scientific to medical, military to communication, lasers are important tools used in many areas. The jobs created associated with laser technology are considered important for country development. Lasers used smaller energy compared with conventional systems. But nowdays it grows to a laser fiber which is $20 \times$ more efficient than the conventional lasers. Aside from the economy, they have a positive impact on the environment. Laser-driven fusion produces no greenhouse gas emissions and thus has a low environmental impact. Also, unlike nuclear power stations, there is no long-lived radioactivity, thereby reducing health risks. Compared with prime competitors of laser technology, such as induction and flame hardening systems, the only fundamental change is the use of a laser for the energy source. Due to throughput, product duality and reproducibility, laser hardening has an economical advantage over conventional methods. For complex and non-linear shapes, laser hardening creates localized heat treatment and small heat input that results in a very fine microstructure, rapid quenching rate, and reduce distortion.

Since conventional hardening method which relies on coal or other fuel-based techniques are not environmentally friendly due to the emission of $\mathrm{CO}_{2}$, laser hardening technique becomes preferable [1]. More than that, currently, the production of hardened metal precision components is done in 3 steps: soft machining, hardening, and finishing. First, the component will pass through soft machining, and then it will be unclamped and delivered to the hardening facility. To obtain the required surface finish and geometrical accuracy, the hardened part is transported back to the machine shop for a finishing operation (e.g., grinding, hard milling, and hard turning, etc.) as shown in Figure 1 [2]. The hardening setup is not in the same machine, often not even in the same workshop as the machining center. This leads to a loss of time when delivering the parts from the machining center to the hardening section. Additionally, it 
induces accuracy error due to misalignment/unclamping during back and forth movement of the part between the machining center and hardening section. This problem can lead to the development of the integrated laser and machining setup at the KU Leuven (Catholic University of Leuven). This machining setup can facilitate the soft machining, hardening, and hard finishing step, saving both cost and time.

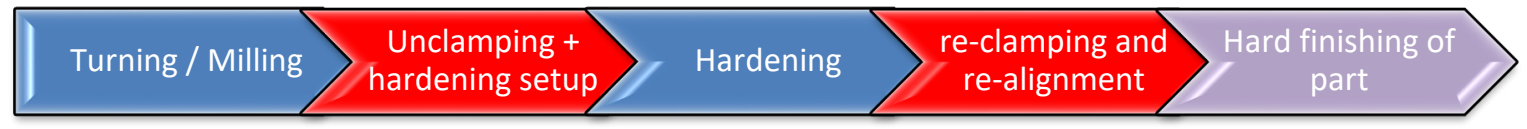

Figure 1 Conventional hardening procedure for metal precision components [2].

\section{Materials and methods}

\section{Unimax}

It is a stainless tool steel that was developed for making the components of injection molds [3]. The composition of this type of stainless steel is shown in Table 1. Several properties were a concern for the hardening process. Although having a rather typical composition of Unimax with only $5 \%$ chromium and no nickel, Unimax is considered as stainless steel [4]. A non-hardened Unimax sample that had approximately $200 \mathrm{HV}$ was the concern for this study. With conventional hardening procedures, it can be hardened up to $600 \mathrm{HV}$ [3]. Therefore, study aims to reach at least the same hardness level as the conventional hardening technique with a comparative advantage of minimized time, self-quenching property, and localized heat input. Ground Unimax samples with a size of $210 \times 35 \times 7 \mathrm{~mm}^{3}$ are used in this research to perform a design of experiment (DOE) to find the optimal laser hardening parameters.

Table 1 Chemical composition of Unimax.

\begin{tabular}{ccccccc}
\hline Chemical Element & C & Si & Mn & Cr & Mo & V \\
\hline Composition (\%) & 0.5 & 0.2 & 0.5 & 5.0 & 2.3 & 0.5 \\
\hline
\end{tabular}

\section{Nd:YAG laser in a machining centre}

The $500 \mathrm{~W}$ Nd:YAG Lumonics laser is implemented into an integrated 5-axis Sauer-70/5 CNC (Computer Numerical Control) machining center, as seen in Figures 3 and 4. The laser can be controlled both manually and using $\mathrm{NC}$ code executed by the milling machine. Due to internal losses, the actual laser power of $500 \mathrm{~W}$ is reduced to $450 \mathrm{~W}$ [5]. Although the laser can produce a varying power output using computer control in theory, it is not very stable at different levels of the machine power; hence, the laser is considered functional at its maximum power of $450 \mathrm{~W}$.

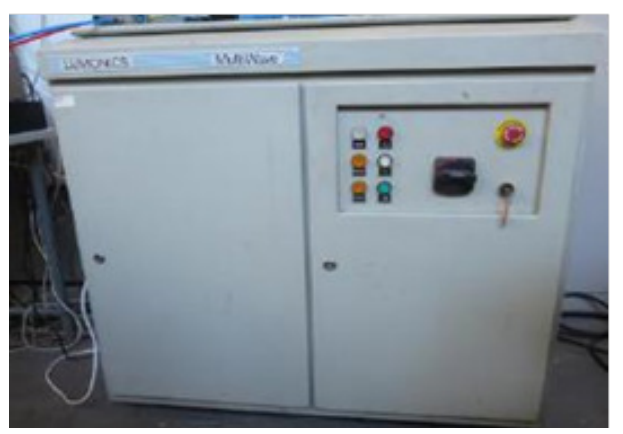

Figure 3500 W Nd:YAG Lumonics. 


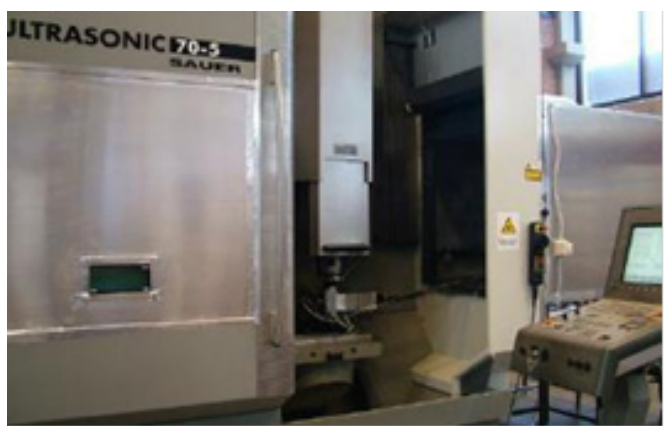

Figure 4 Integrated 5-axis CNC milling machine.

\section{Graphite coating}

To increase the absorption of the workpiece surface to a known level of about $80 \%$ [4], the metal is coated with graphite 33. This is an aerosol spray from Kontakt Chemie ${ }^{\circledR}$ consisting of a thermoplastic binder and electrically conductive graphite powder. Due to its dark black color, it helps reduce the reflection, allowing more energy to be absorbed by the workpiece [6].

\section{Roughness measurement}

The surface roughness has been evaluated using Rt-values obtained with a Tailor Hobson roughness measurement machine from KU Leuven, which is used in manufacturing precision metrology instruments as shown in Figure 5. The laser tracks are made along with the workpieces for every $30 \mathrm{~mm}$ gap between each line. The roughness measurement is taken 3 times on each sample to reduce the possible errors so that the mean value is recorded.

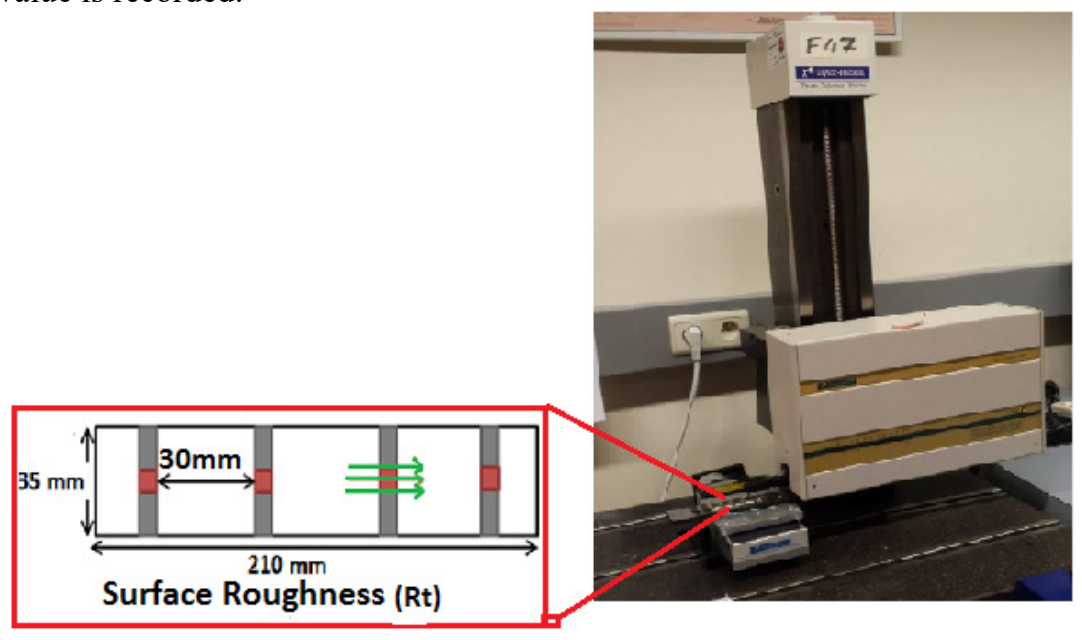

Figure 5 Tailor Hobson roughness measurement equipment.

\section{Methods}

At KU Leuven, an integrated laser hardening with the 5-axis milling machine was developed [7]. Firstly, the reaction of blocks of Unimax is investigated when treated with certain speeds and spot sizes of the laser head, to determine if it reacts similarly to other steels. At the same time, the setup enabled the verification of the combined parameter results made in the simulation. The previous study result on low alloyed, carbon-rich steel, which is easy to harden, now extended towards the Unimax stainless steel. A proof of concept was conducted on C-45 steel, indicating that it was well capable of hardening C-45 steel, outperforming conventional hardening techniques. A study executed with a pulsed Nd:YAG (neodymium-doped yttrium aluminum garnet; Nd:Y3A15O12) laser on AISI 420 stainless steel suggests that it is possible to harden stainless steel although only $490 \mathrm{HV}$ was achieved with laser hardening compared to traditional hardening methods that reached up to 500 - $550 \mathrm{HV}$ [8].

To harden the metal, first, the material was exposed to the temperature in between the critical point $\left(\mathrm{AC}_{3}\right.$, Austenization temperature) and the melting point. From specific heat plots for Unimax, supplied by 
the department of material science of the KU Leuven, its melt temperature was estimated at around 1700 ${ }^{\circ} \mathrm{K}$, as illustrated in Figure 6.

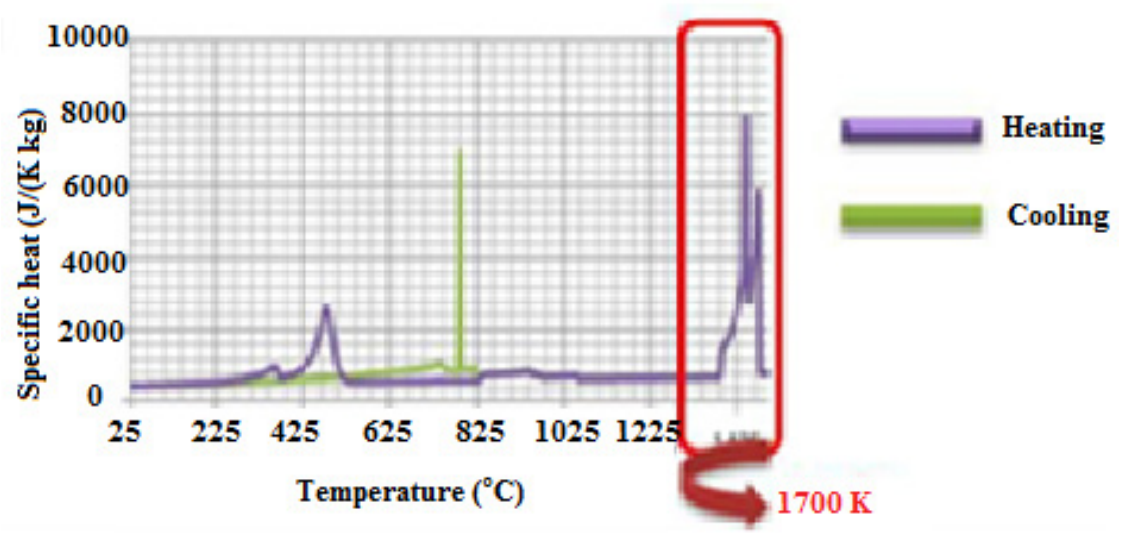

Figure 6 Specific heat Vs temperature during heating and cooling of Unimax stainless steel.

The critical temperature of Unimax based on the carbon content $(0.5 \%)$ was obtained from the combining result of the iron carbide diagram and the cooling rate of Unimax at $770{ }^{\circ} \mathrm{C}$.

Physical testing of samples costs a lot of time and money; this is due to the high number of tests that needs to be executed to find optimum ranges of parameters. Therefore, the experiments were $1^{\text {st }}$ run as a computer simulation in the Multiphysics software COMSOL $^{\mathcal{C}}$. Symmetry functions were applied to reduce calculation time and allow easier visual inspection. In this program, the transient heat transfer caused by the Nd:YAG laser having $1064 \mathrm{~nm}$ wavelength and $450 \mathrm{~W}$ input power was modeled as a tophat distributed function. Both the simulated and real beam profiles are shown in Figures 7(a) and 7(b) respectively.

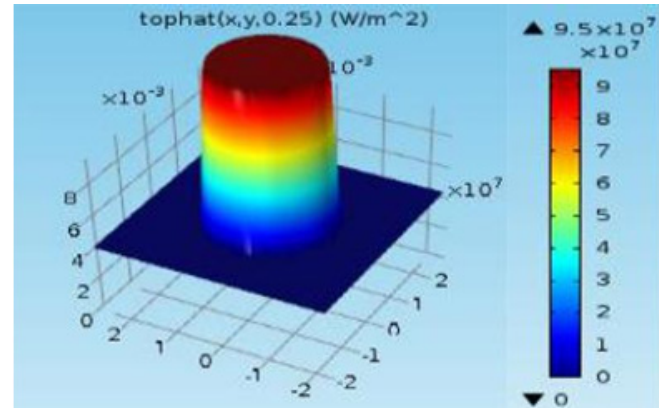

(a)

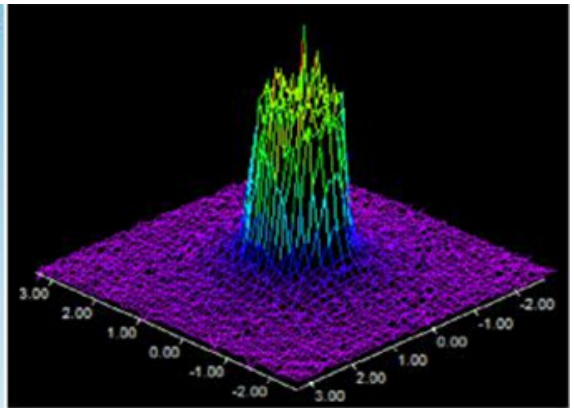

(b)

Figure 7(a) Simulated top head power density; (b) The measured real beam profile.

\section{Beam analysis}

To determine the spot size of the beam, thermal imaging paper or electrical beam analysis instruments was selected. Even though thermal imaging paper is quick and easy to use with a major drawback of exposure time and laser power, it needs to be carefully adjusted to avoid burning away the paper.

\section{Sample preparation}

First, the laser traces the sample block along the direction are indicated in Figure 8. Then, heattreated metal was cut by wire-EDM (Electrical Discharge Machining) into small sections of $10 \times 10 \mathrm{~mm}^{2}$. These samples were, then, embedded in a polymer Technovit, in such a way that the surface perpendicular to the heat-treated surface laid on the flat outside of the sample, as shown in Figure 9. 
Subsequently, the samples were ground, polished, and etched. These procedures included grained polishing papers, diamond slurries, and OPS, a form of oxide polishing in which co-operation takes place between polishing grains and a chemical reagent that provides an absolute scratch and deformation-free preparation. Finally, etching with nitric acid or Villella's reagent made the grain structure more visible. Since the etched surface was a cross-section of the hardened zone, martensitic, pearlite, and ferrite structures became visible. The hardened region was noticeable to the naked eye of a careful inspector but better analyzed with a microscope.

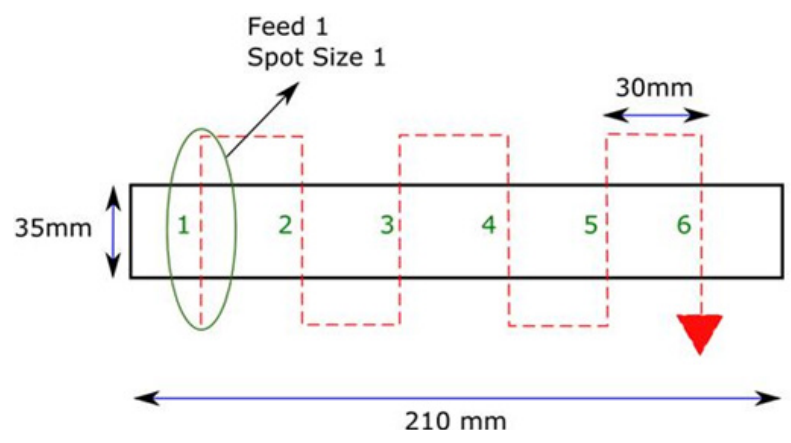

Figure 8 Track directions on Unimax.

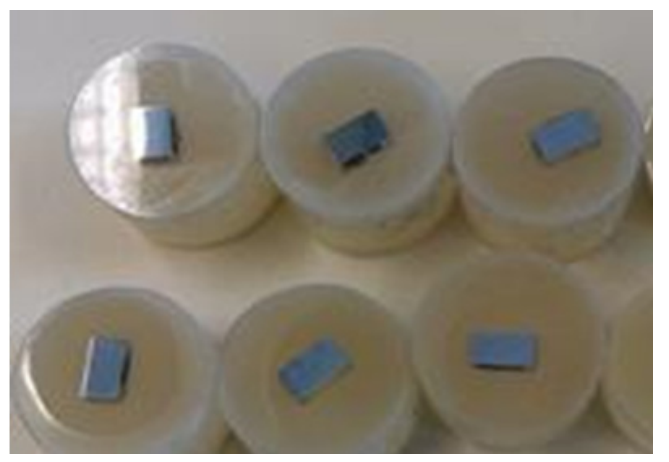

Figure 9 Prepared specimens for the hardness test.

\section{Design of experiment}

Since the traverse speed and spot size are the potential parameters to control the power density of the laser, 2 process parameters, spot size, and traverse speed of the laser with 4 and 3 levels respectively are selected to run a series of experiments. To reduce the random error, the experiment was replicated 3 times. Finally, this led to 36 tests as more deeply seen in Table 2.

Table 2 Parameters of samples as conducted in the randomized run order.

\begin{tabular}{|c|c|c|c|c|}
\hline \multirow{6}{*}{ 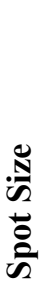 } & & \multicolumn{3}{|c|}{ Traverse Speed (mm/min) } \\
\hline & & 100 & 150 & 400 \\
\hline & $2164 \mu \mathrm{m}$ & $3 \times$ & $3 \times$ & $3 \times$ \\
\hline & $2169 \mu \mathrm{m}$ & $3 \times$ & $3 \times$ & $3 \times$ \\
\hline & $2288 \mu \mathrm{m}$ & $3 \times$ & $3 \times$ & $3 \times$ \\
\hline & $2412 \mu \mathrm{m}$ & $3 \times$ & $3 \times$ & $3 \times$ \\
\hline
\end{tabular}




\section{Results and discussion}

In Figure 10, the final selected combinations of traverse speed and spot sizes are shown as a function of temperature. It is clearly shown that the cooling rate is increasing for a fast traverse speed of the laser while the maximum temperature is decreasing, and the reverse is true for slow traverse speed at a constant spot size. Similarly, at a fixed traverse speed, the maximum temperature increases with a decrease in the spot size of the laser.

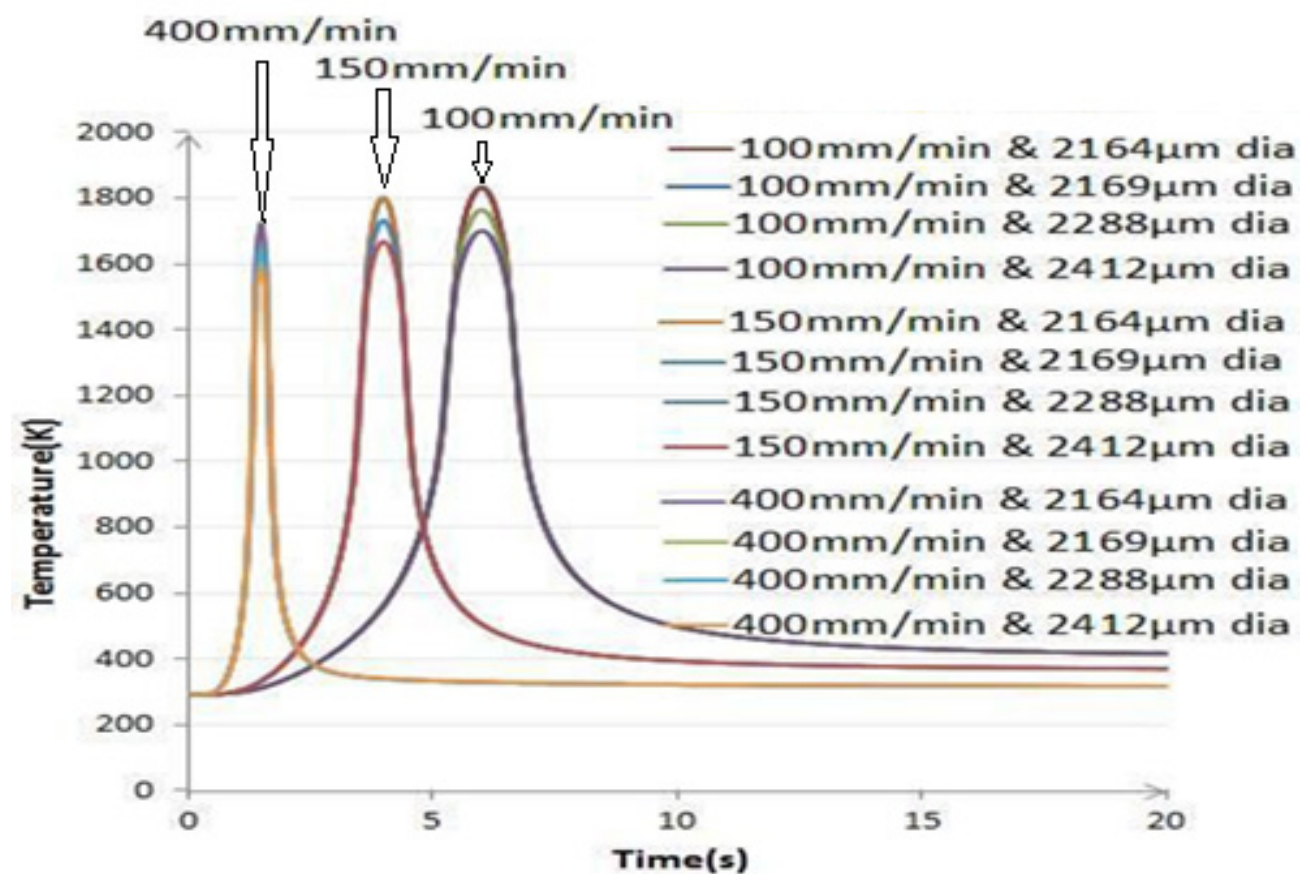

Figure 10 The simulated cooling rate as a function of different speeds and spot sizes of the laser.

\section{Microhardness results}

The Vickers hardness is decided to be measured every $60 \mu \mathrm{m}$ starting $60 \mu \mathrm{m}$ below the surface and the maximum can be assumed to be at or just below the surface as shown in Figure 11, the resulting hardness considered here is a mean of the 2 first measurements, thus the mean between the hardness at 60 $\mu \mathrm{m}$ below the surface and $120 \mu \mathrm{m}$ below the surface, therefore approximately the hardness at $90 \mu \mathrm{m}$ below the surface. The reason behind the idea of taking the arithmetic mean of the first 2 samples was to reduce human errors even more than just by looking at the results from the 3 replicas. Due to the setup of the hardness tester, steps of $60 \mu \mathrm{m}$ were easiest to set, which means accidental measurements at different heights due to human errors were unlikely. The consequent arithmetic means at $90 \mu \mathrm{m}$ also helped to produce comparable results to the study of Bouquet et al. [5] who took the mean of measurements at 50 and $130 \mu \mathrm{m}$ below the surface when conducting experiments on the same laser hardening and machining center when testing on C-45 steel. 


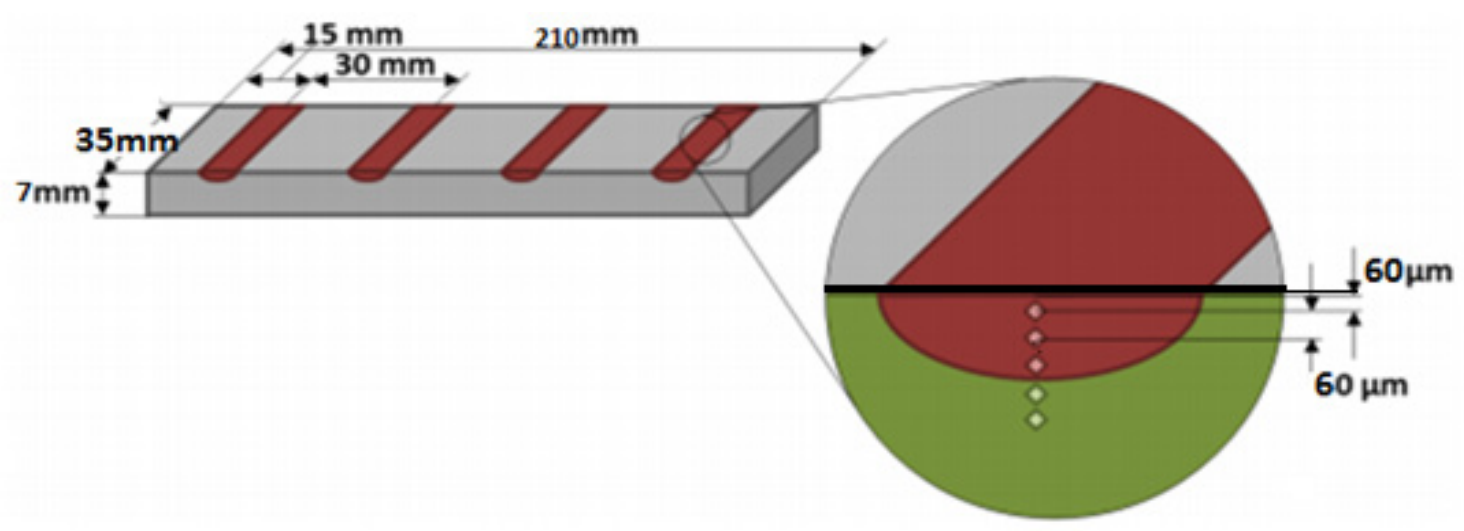

Figure 11 Vickers hardness measurement gaps.

The results, as illustrated in Figure 12, show an increased hardness with decreasing speed and decreasing spot size without any great outliers in the replicates. The bar graphs show the mean of the 3 replicas and the red and pink dots indicate the values of each specific sample. When looking at the hardness values, one can notice that the lowest hardness value is at a comparable level to the hardness of the untreated parent material and the highest hardness; although desired, it is unusableas it melts pools on their surface which causes unwanted deformation. Therefore, the highest hardness can be found at a speed of $150 \mathrm{~mm} / \mathrm{min}$ and a distance of $110 \mathrm{~mm}$ between the head of the laser and workpieces, or spot sizes of $2169 \mu \mathrm{m}$ respectively. It has been measured to be around $650 \mathrm{HV}$.

From the analysis of variance, it becomes clear that speed and distance, or spot size respectively, have. 05 significant levels on the hardness. However, there is no interaction effect, as can be seen in Figure 13.

\section{Depth of hardening and melt}

Via optical inspection and cross-referencing with the results from the hardness measurements at greater distances from the surface, the depth of the hardened zone has been obtained.

Figure 14 illustrates the hardened depths as a function of parameters similar to the hardness values in Figure 12 which describes no great outliers but an increase of depth at a decrease of speed and spot size.

To analyze the effect of the laser treatment on the metal, one can make use of several standard microscope types. When looking at a cut section perpendicular to the heat-treated surfaces with the aid of a microscope, the grain structure of the metal becomes visible, as shown in Figure 14(b). Thus, one can determine, if a melt pool has occurred due to overheating the metal, and where the Martensitic phase has formed, and thus where the hardened zone is located. Most microscopes also offer tools to directly take measurements from these images, such as the distance between 2 points, so that the depth of hardening can be directly obtained.

Similar to the hardness results, it has a broad range from no hardness depth to a limit in depth when melt occurs. When neglecting the samples with melt, the deepest depth of hardening was found at a speed of $150 \mathrm{~mm} / \mathrm{min}$ and a distance of $110 \mathrm{~mm}$, or a spot size of $2169 \mu \mathrm{m}$. It has been measured with a value of $250 \mu \mathrm{m}$. 


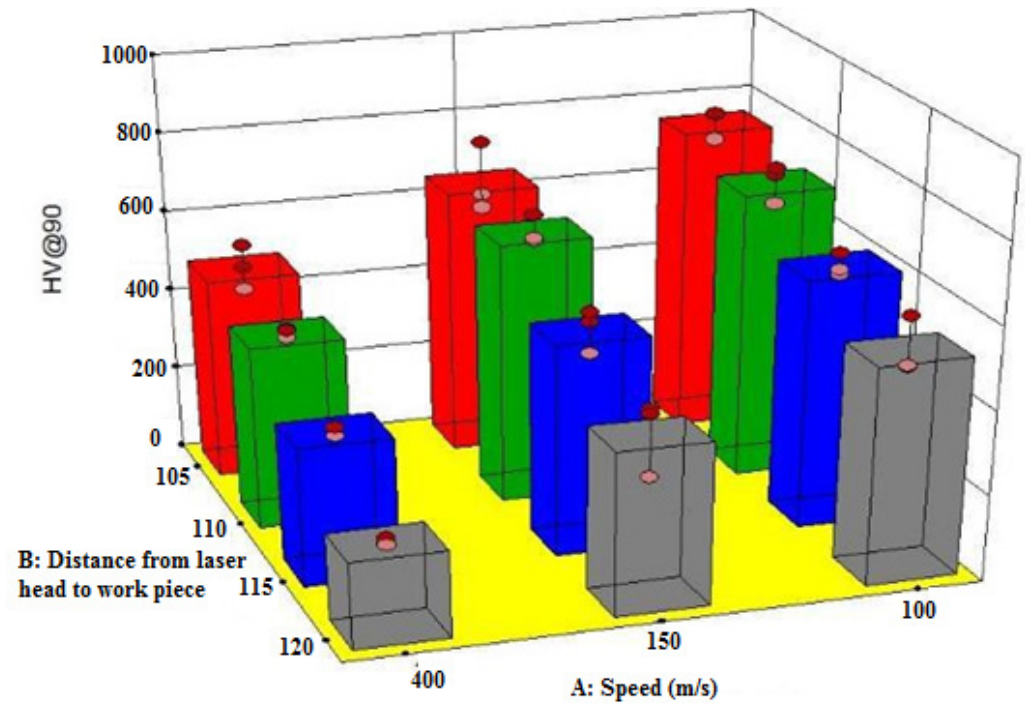

Figure 12 Microhardness (HV) at $90 \mu \mathrm{m}$ below the surface in the function of traverse speed $(\mathrm{mm} / \mathrm{min})$ and distance between material and laser head $(\mathrm{mm})$.

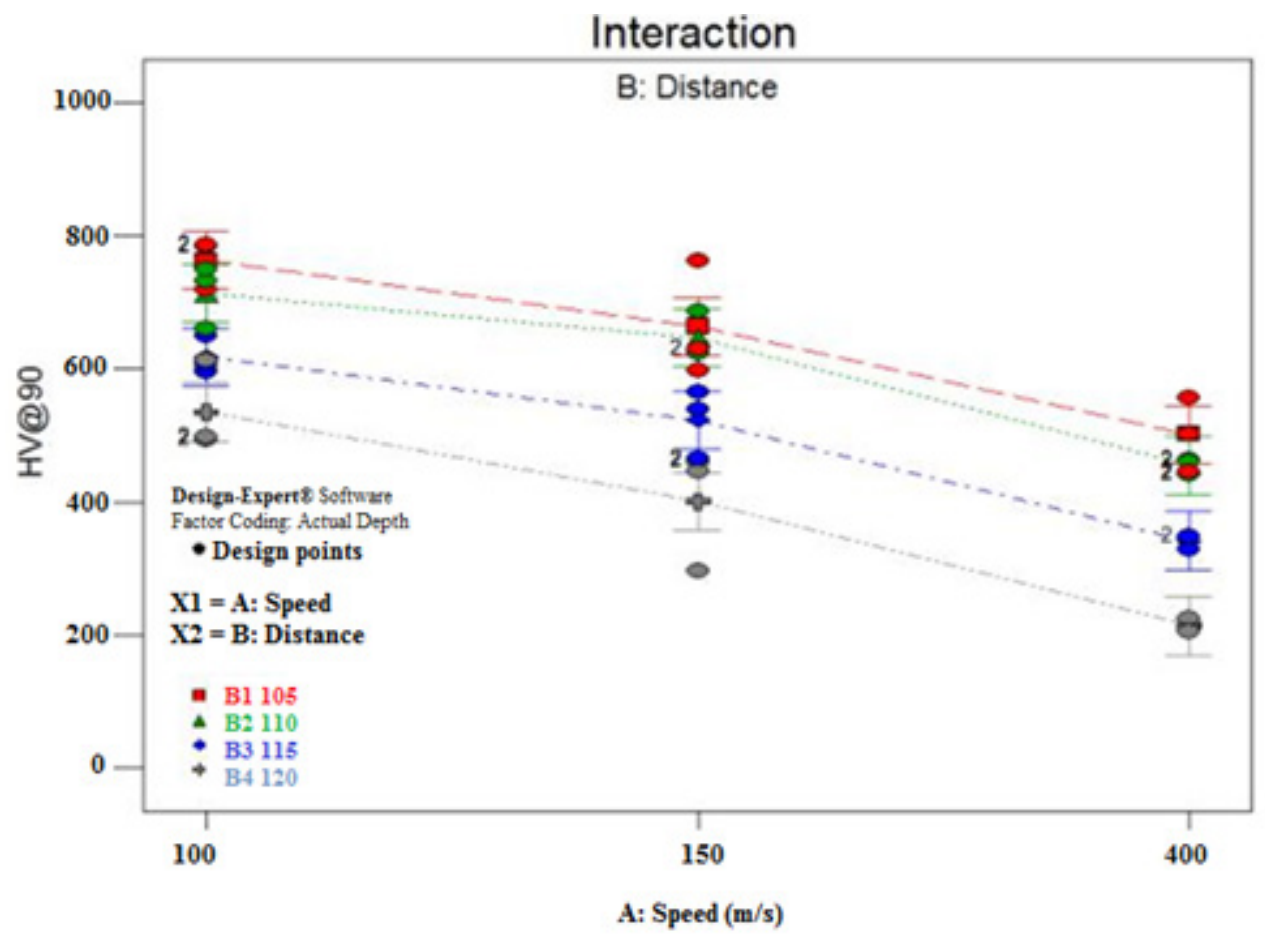

Figure 13 Interaction plot hardness. 


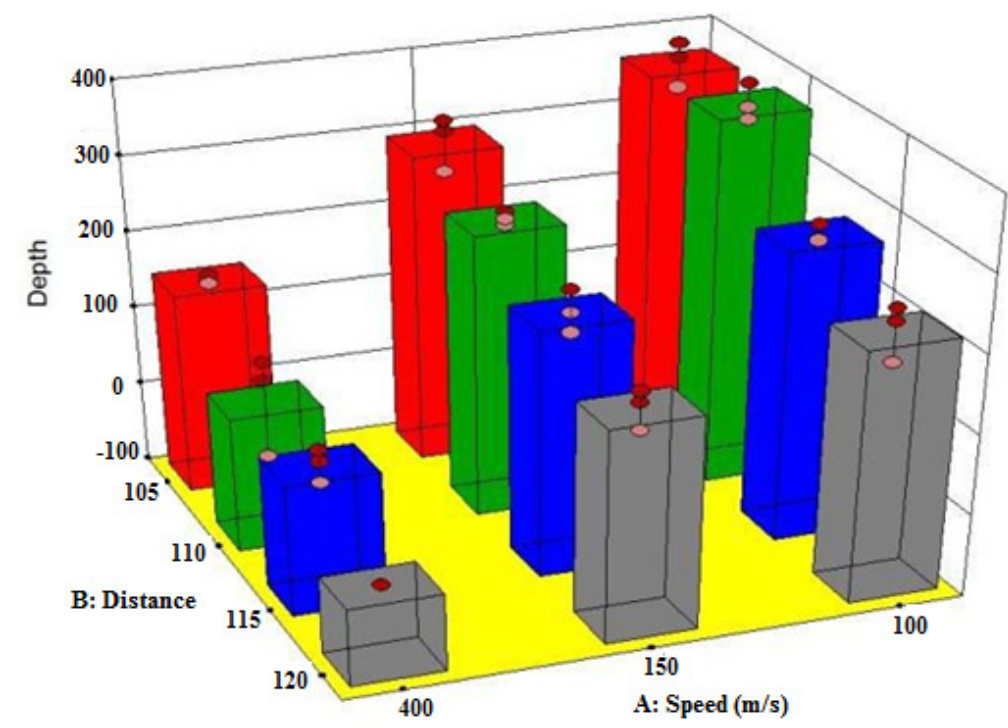

(a)

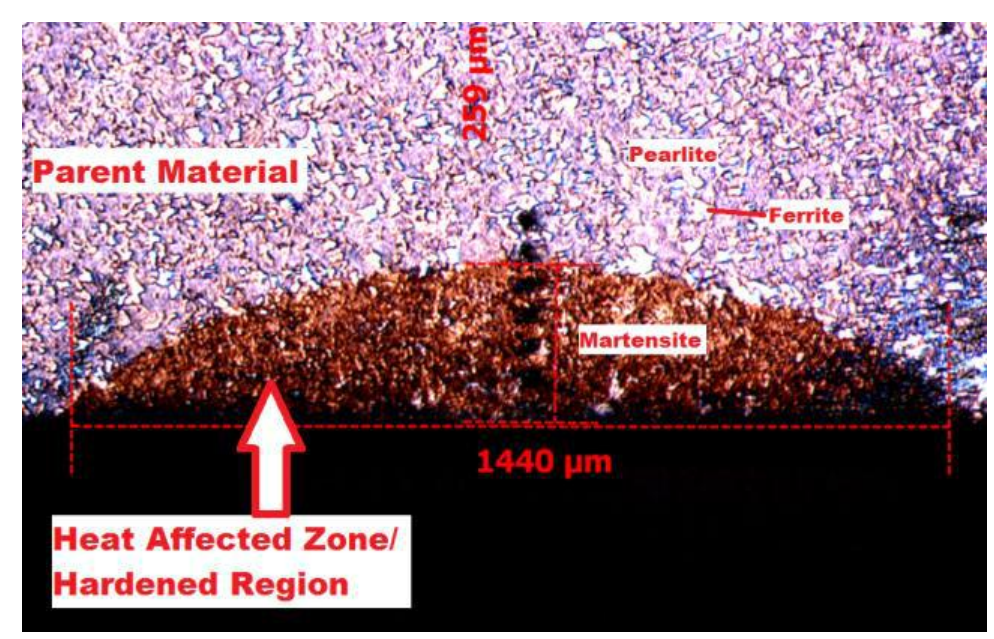

(b)

Figure 14 (a) Depth of hardening $(\mu \mathrm{m})$ in the function of traverse speed $(\mathrm{mm} / \mathrm{min})$ and distance between material and laser head ( $\mathrm{mm}$ ) and (b) Grain structures under the microscope.

Based on the analysis of variance, it becomes clear that speed and spot size have a significant influence on the depth of hardening; however, there is no interaction effect, as can be seen in Figure 15. 


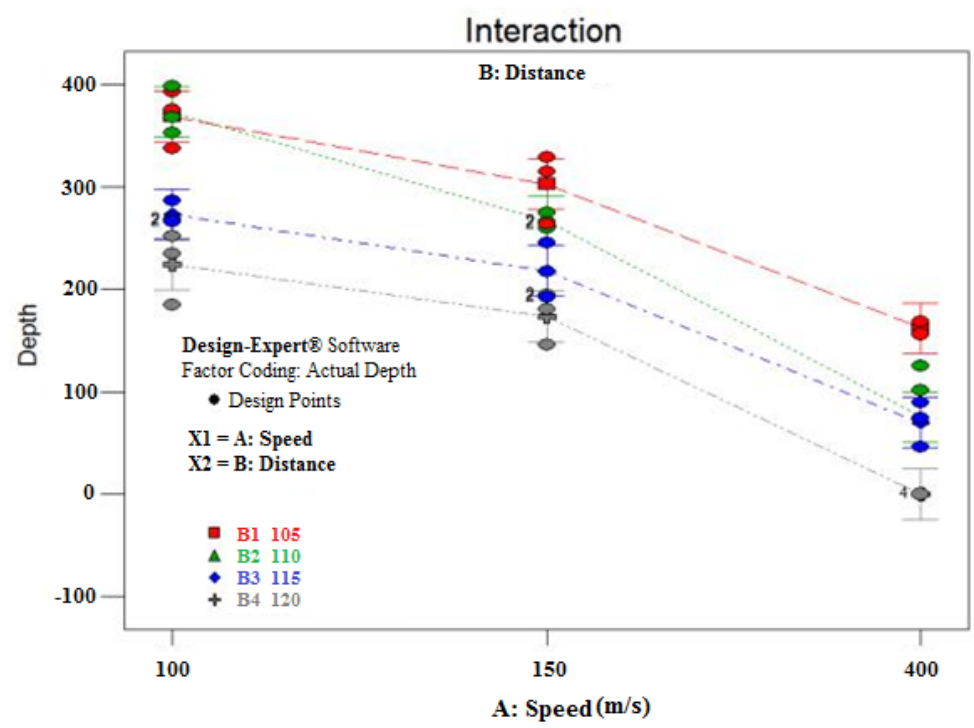

Figure 15 Interaction plot for depth of hardening.

To confirm the physical result with the simulation, an isotherm temperature of $1220 \mathrm{~K}$ was taken for speeds of 100,150 and $400 \mathrm{~mm} / \mathrm{min}$. This depth of the maximum curve of isotherm temperature compared to the material surface can be measure in COMSOL. Consequently, the percentage difference between the simulation depth and real test depth is calculated, as can be seen in Figure 16. Especially for a speed of $400 \mathrm{~mm} / \mathrm{min}$ the difference is quite big. This is due to the constant isotherm that was assumed for all 3 speeds. However, the isotherm temperature may be smaller at higher speeds and lower at slower speeds, as the holding time for material heating also changes depending on the traverse speed. Therefore, the depth of hardening obtained by the simulation will not be a good prediction based on the isotherm value of $1220 \mathrm{~K}$. However, especially when looking at the results for 100 and $150 \mathrm{~mm} / \mathrm{min}$, one can assume, that the simulation predicts quite realistic results. The numerical comparison between the simulated and measured values can be seen in Table 3.

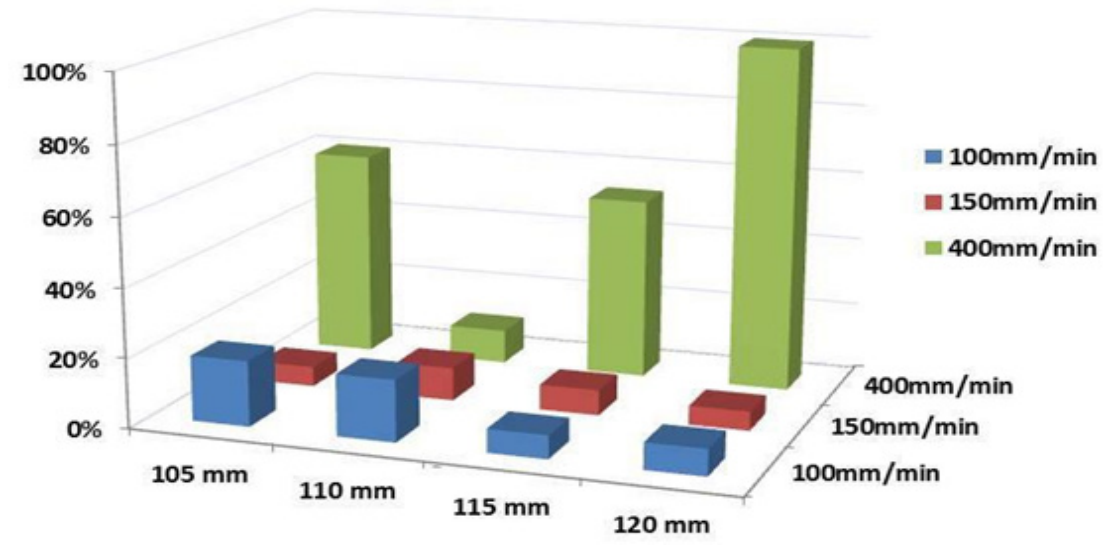

Figure 16 Percent difference between simulated and measured values of the depth of hardening. 
Table 3 Error in percentage (\%) between simulated and measured value.

\begin{tabular}{ccccccc}
\hline & $\begin{array}{c}\text { Simulated/ } \\
\text { Measured }\end{array}$ & $\begin{array}{c}\text { Difference } \\
(\%)\end{array}$ & $\begin{array}{c}\text { Simulated/ } \\
\text { Measured }\end{array}$ & $\begin{array}{c}\text { Difference } \\
(\%)\end{array}$ & $\begin{array}{c}\text { Simulated/ } \\
\text { Measured }\end{array}$ & $\begin{array}{c}\text { Difference } \\
(\%)\end{array}$ \\
\hline & $100 \mathrm{~mm} / \mathrm{min}$ & & $150 \mathrm{~mm} / \mathrm{min}$ & & $400 \mathrm{~mm} / \mathrm{min}$ & \\
$105 \mathrm{~mm}$ & $302.08 / 373$ & 19.0 & $283 / 266.67$ & 5.77 & $190.14 / 75.33$ & 60.40 \\
$110 \mathrm{~mm}$ & $302.08 / 368$ & 17.9 & $273.46 / 302.67$ & 9.65 & $179.99 / 162$ & 9.90 \\
$115 \mathrm{~mm}$ & $254.38 / 273$ & 6.80 & $235.30 / 218$ & 7.35 & $147.84 / 69.67$ & 52.87 \\
$120 \mathrm{~mm}$ & $206.67 / 224$ & 7.70 & $183.45 / 173.33$ & 5.52 & $97.27 / 0$ & 100 \\
\hline
\end{tabular}

\section{Discussion}

According to Figures 12 and 14(a), slow traverse speed and small laser spot size show a higher hardness and depth of hardening values respectively. This is because the smaller spot size will have a higher heat density and slower traverse speed will have sufficient time to interact with the workpiece to raise the temperature of the sample. However, those parameters cannot be considered as an optimal value because it always ends up with the sample melt. Finally, the optimal solution for the unmelt sample gives the hardness of $650 \mathrm{HV}$ which is a little bit above the conventional hardening value but with a multiple advantage of laser hardening.

\section{Conclusions}

Laser hardening of Unimax is possible. Besides, but it shows similar behaviors and results as any other common type of steel where the hardness values similar to the ones from conventional hardening techniques. From this study, hardeningUnimax stainless steel can be done up to $650 \mathrm{HV}$ while it is 600 $\mathrm{HV}$ using the conventional hardening technique. It is possible to conclude from the result that the hardness of more than $780 \mathrm{HV}$ can be obtained from the laser harness of Unimax. Yet, a higher value comes up with a rough surface which leads to finding the optimal solution using the melt/unmelt results.

The depth of hardening and Vickers hardness (HV) increased with the smaller spot size and traverse speed of the laser, but this resulted in a melt on the surface of the hardened metal. The optimal value to achieve $650 \mathrm{HV}$ with no melt on the surface of the metal was $2169 \mu \mathrm{m}$ and $150 \mathrm{~mm} / \mathrm{min}$ laser speed. Exploring the effect of laser hardening on the inclined surface of the same metal block is recommended for the future study.

\section{Acknowledgements}

We would like to express our gratitude to our co-supervisors Dr. Jan Bouquet for his constant support during the practical execution of tests as well as in sharing his knowledge and experience from previous theses with us and Jef Loenders for his feedback helpful suggestions throughout the process. We also would like to thank Dries Van Camp who gave us suggestions and help during preparation, testing, and analysis of the samples. Furthermore, we would like to thank Professor Bert Lauwers for promoting this research. Our best regards also go to the COMSOL support team for their quick and precise answers as well as to all the other people that were so kind in helping us out with one or the other question.

\section{References}

[1] PD Babu, KR Balasubramanian and G Buvanashekaran. Laser surface hardening: A review. Int. J. Surf. Sci. Eng. 2011; 5, 131-51.

[2] J Bouquet, DV Camp, B Peeters, J Massa and B Lauwers. Machining and selective laser hardening of complex shaped components on a multi-axis machining center. In: Proceedings of the MTTRF 2016 Annual Meeting, San Francisco CA, USA. 2016, p. 90-100.

[3] Uddeholm Unimax data sheet. Available at: http://www.uddeholm.com/files/ PB_unimax_english.pdf, accessed April 2020.

[4] D Bergström, J Powell and AFH Kaplan. The absorptance of steels to Nd:YLF and Nd:YAG laser light at room temperature. Appl. Surf. Sci. 2017; 253, 5017-28.

[5] J Bouquet, DV Camp, H Vanhove, S Clijsters, M Amirahad and B Lauwers. Development of a flexible laser hardening \& machining centre and proof of concept in C-45 steel. In: Proceedings of the $8^{\text {th }}$ International Conference on Photonic Technologies LANE, Fürth, Germany. 2014, p. 1-11. 
[6] JD Griffiths, S Edwardson, T Boegelein, G Dearden and K Watkins. The effect of graphite burns off on multi pass laser forming. In: Proceedings of the International Workshop on Thermal Forming and Welding Distortion, Bremen, DE, Germany. 2011.

[7] V Camp. Integration of laser hardening in a multi-axis machining center. Wise tool. Available at: https://www.wisetool.com/surfacefinish.htm, accessed April 2020.

[8] B Mahmoudi, MJ Torkamany, ARSR Aghdam and J Sabbaghzade. Laser surface hardening of AISI 420 stainless steel treated by pulsed Nd:YAG laser. Mater. Des. 2010; 31, 2553-60. 